\title{
VARIA
}

\author{
DOS LIENZOS FIRMADOS POR ALONSO DEL ARCO \\ EN LA PARISINA IGLESIA SAINT-FRANÇOIS-DE-SALES *
}

El inventario detallado realizado en las iglesias de París por los conservadores des Oeuvres d'Art Religieuses et Civiles del ayuntamiento de la capital francesa, puede reservar gratas sorpresas. Muy reciéntemente Guénola Groud, conservateur du Patrimoine y su equipo, pudieron localizar en la «Salle des mariages» de la nueva iglesia de Saint-François-de-Sales (París, $\mathrm{XVII}^{\text {ème}}$ ) dos importantes lienzos de medio punto, la Adoración de los Pastores (Fig. 2) y la Adoración de los Magos (Fig. 1) ${ }^{1}$, firmados por el pintor Alonso del Arco (1635-1704) colaborador y discípulo de Antonio Pereda.

Existen en efecto dos iglesias Saint-François-de-Sales. La más antigua, de 1873, está situada en la calle Brémontier mientras que la más reciente, construída entre 1911 y 1913, tiene su entrada principal en la calle Ampère ${ }^{2}$. Las dos comunican por varios pasillos y sacristías entre las cuales la «Salle des mariages» que hoy en día ya no se utiliza para las bodas puesto que los registros parroquiales se firman actualmente en el propio altar de la iglesia. Las investigaciones realizadas por Guénola Groud en los archivos no han permitido hasta la fecha saber cuando y como llegaron allí los dos lienzos de Alonso del Arco.

Como ocurre con la mayoría de los artistas del siglo xviI, debemos a Palomino las primeras noticias sobre Alonso del Arco ${ }^{3}$, apodado el «Sordillo de Pereda» por ser sordomudo. Palomino conoció personalmente al pintor madrileño, formado en el taller de Pereda. Adquirió fama como retratista aunque se conozcan pocos retratos suyos. Asimismo hizo cuadros de historia y de devoción de calidad muy desigual, motivada por la cantidad de encargos y lo apresurado de su ejecución. Según Palomino sabemos que Alonso del Arco utilizaba modelos grabados para sus pinturas: «que aunque se hallan muchos cuadros suyos tomados, o hechos por estampas, es porque los discípulos los hacían por ellas y el las retocaba, o las acababa» ${ }^{4}$. Palomino asegura que los que recurrían a las estampas eran los asistentes, aunque resulta patente que la mayoría de los pintores españoles del siglo XVII emplearon grabados a la hora de com-

\footnotetext{
* Agradecemos a Pierre Curie, conservateur du Patrimoine, por habernos indicado este hallazgo.

1 Adoración de los pastores, lienzo de medio punto, 148x158, firmado abajo en el centro: «Alonso del Arco f.»; Adoración de los Magos, lienzo de medio punto, $143 \times 153$, firmado abajo a la derecha «Alonso del Arco f.».

${ }^{2}$ Recordemos que desde 1905, fecha de separación de la Iglesia y del Estado en Francia, las iglesias y su mobiliario pertenecen al Estado. Sin embargo los templos construidos despues de 1905 son propiedad de la Iglesia.

3 Sobre Alonso del Arco, ver Galindo, N., «Alonso del Arco», Archivo Español de Arte, 1972, pp. 347-385. Con posterioridad han sido identificadas en España varias obras firmadas del pintor madrileño.

${ }^{4}$ Palomino, El Parnaso español laureado, Madrid, 1724, t. III, éd. 1988, p. 478.
} 

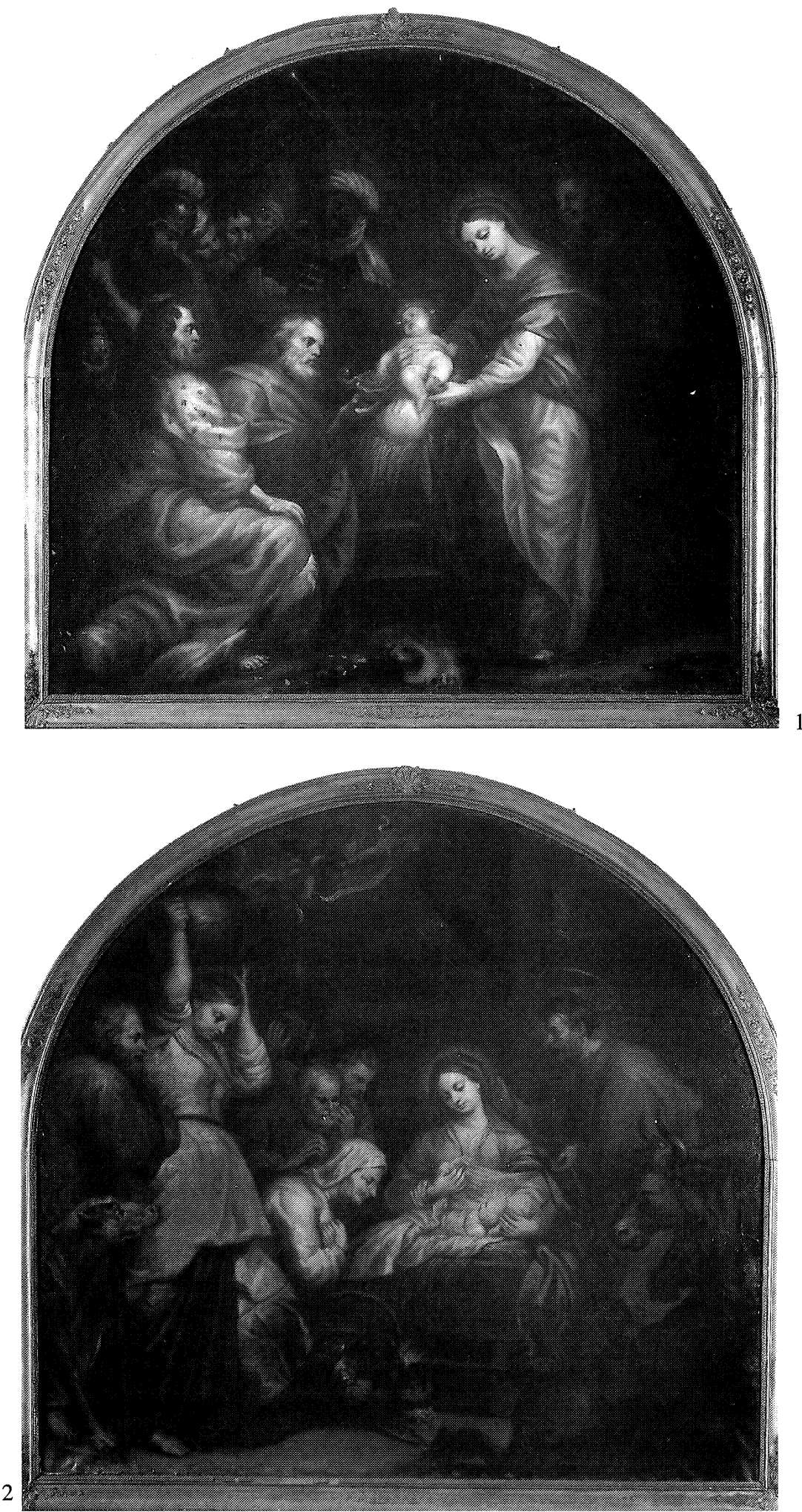

Fig. 1. Alonso del Arco, Adoración de los Reyes. París, iglesia Saint-François-de-Sales. Fig. 2. Alonso del Arco, Adoración de los pastores. París, iglesia Saint-François-de-Sales.

AEA, LXXVII, 2004, 307, pp. 301 a 326 
poner sus cuadros. De hecho en los dos lienzos de la iglesia parisina, Alonso del Arco utiliza conocidos grabados flamencos sobre composiciones rubenianas.

La Adoración de los pastores está realizada a partir de la estampa de Lucas Vorsterman I sobre la composición de Rubens conservada en el museo de Marsella (Fig. 3) ${ }^{5}$. Los pintores andaluces utilizaron a menudo esta estampa ${ }^{6} \mathrm{y}$ el propio Alonso del Arco se sirve de ella para la también firmada Adoración de los pastores de la iglesia de San Miguel de Valladolid. Este último cuadro, de forma rectangular apaisada, es una copia fiel, aunque en sentido inverso, del cuadro original de Rubens, lo que acredita la utilización de la estampa de Lucas Vorsterman ${ }^{7}$. La forma de medio punto del cuadro parisino ofrece al pintor español la ocasión de modificar un poco la composición, cortando a la izquierda la figura del pastor, pero conservando el mastín y añadiendo una figura de angelito con una banderola en la parte superior.

Para componer la Adoración de los Magos, Alonso del Arco se inspira también en un cuadro de Rubens actualmente conservado en el museo del Louvre ${ }^{8}$. La composición igualmente invertida se basa en un grabado, probablemente el de Schelte a Bolswert (Fig. 4), pero también podría tratarse de la estampa de Willen Panneels a partir del lienzo rubeniano. Asimismo Murillo escogió algunos elementos de estos grabados para componer su Adoración de los Reyes del museo de Toledo (Ohio), aunque no los copia servilmente como Alonso del Arco ${ }^{9}$.

La fiel utilización de las estampas rubenianas por el pintor madrileño no impide que los dos cuadros recién descubiertos tengan su estilo propio. A través del modelo copiado aparecen los mismos tipos humanos, los mismos rasgos físicos de expresión dulce, los rostros de forma triangular, con frente ancha, ojos abombados y boca pequeña típicos de Alonso del Arco. A pesar del bárniz espeso y amarillento, los colores de los cuadros son agradables y compensan la falta de imaginación de las composiciones del pintor madrileño.

Como hemos dicho anteriormente no sabemos como llegaron estos lienzos a la sacristía de Saint-François-de-Sales, quizás como regalo de un feligrés o de un cura mecenas de la iglesia. Al parecer Saint-François-de-Sales tuvo a finales del siglo XIX y a principios del siglo xx tres párrocos que fueron verdaderos protectores de las artes. L'Abbé Van den Brule, cura desde 1875 hasta 1896, l'Abbé Pagis, 1897-1919, quien construyó el nuevo templo de la calle Ampère y Monseigneur Loutil, 1919-1959, una de las figuras más relevantes y admiradas de la Iglesia en Francia de su tiempo. Recordemos que el barrio, situado al oeste de la capital francesa, se construyó y amplió a finales del siglo XIX y sus habitantes pertenecen desde entonces a la burguesía acomodada de París.

Los cuadros salieron probablemente de España durante la guerra de la Independencia o después de la desamortización de Mendizabal. En el siglo xIx Alonso del Arco no era un desconocido para los franceses: Quilliet le consagra una biografía relativamente importante en su diccionario de $1816^{10} \mathrm{y}$ su nombre aparece en algunas ventas parisinas de este mismo siglo. Después de Palomino, Ponz y Ceán Bermúdez dieron a conocer el catálogo de su obra reconstruída en 1972 por Natividad Galindo. Alonso del Arco fue un pintor prolífico que solía firmar sus lienzos, razón por la cual es frecuente la publicación de nuevas obras suyas, sin embargo

\footnotetext{
${ }^{5}$ Estampa fechada en 1620. Rubens pinta esta Adoración de los pastores como predela del retablo de la Adoración de los Reyes para la iglesia San Juan de Malinas. Fue sustraído en 1794 por las tropas francesas.

6 Ver Navarrete, B., La pintura andaluza del siglo xviI y sus fuentes grabadas, Madrid, 1998, pp. 190-191, figs. 347349 .

7 Valdivieso E., «Tres pinturas de Alonso del Arco», Boletín del Seminario de Estudios de Arte y Arqueología, 1970, pp. 521-522, lám. I.

${ }^{8}$ El cuadro de Rubens fue pintado hacia 1625-1629 para el altar mayor de la iglesia de las Anonciades de Bruselas. Fue comprado en 1777 para la colección de Louis XVI.

9 Navarrete B., La pintura... op. cit., pp. 194-195, figs. 360 y 363.

${ }^{10}$ Quilliet F., Dictionnaire des peintres espagnols, Paris, 1816, pp. 8-9.
}

AEA, LXXVII, 2004, 307, pp. 301 a 326 



Fig. 3. Lucas Vorsterman I, Adoración de los pastores, 1620. Grabado sobre composición de Rubens. Fig. 4. Schelte a Bolswert, Adoración de los Reyes. Grabado sobre composición de Rubens. 
los dos cuadros de la iglesia Saint-François-de-Sales han permanecido inéditos. Ahora bien si no sabemos nada de la historia reciente de estas Adoraciones, podemos intentar localizar su origen a partir de las descripciones de las iglesias madrileñas por Ponz, Palomino o Ceán Bermúdez. La forma de medio punto puede servir de indicación.

Palomino indica que «Son de su mano todas las pinturas que están en el retablo, lunetos y pechinas de la capilla de Nuestra Señora de la Novena, que es de los Comediantes de esta corte, sita en la parroquial de San Sebastián» ${ }^{11}$. Ponz describe en la misma parroquia de San Sebastián «la capilla llamada de la Novena, en donde lo mejor son algunas pinturas de Alonso del Arco». Este autor no precisa la forma de dichos cuadros mientras que en el Convento de San Felipe el Real, el mismo Ponz, hablando de Joseph García, añade «también son suyos algunos de los lunetos; y otros de Alonso del Arco» ${ }^{12}$. Por fin Ceán Bermúdez en su catálogo de las obras del pintor cita en San Sebastián «Todas las pinturas del retablo, lunetos y pechinas de la capilla de nuestra señora de la Novena» y en San Felipe del Real «Siete quadros de los lunetos en los ángulos del claustro baxo» ${ }^{13}$. Por desgracia ninguno de estos autores indica el tema de los cuadros pero la Adoración de los pastores como la Adoración de los Reyes pueden perfectamente pertenecer a ciclos de la vida de la Virgen por lo que nos inclinamos a pensar que los dos lienzos recién descubiertos estuvieron en la iglesia de San Sebastián que era la parroquia del pintor y donde fue sepultado. Dicho templo sufrió grandes daños materiales en 1936 quemándose completamente los altares y retablos pero probablemente los cuadros de Alonso del Arco ya no estarían allí. Galindo ya apuntaba en 1972 que pocas obras de la mano de Alonso del Arco se conservaban in situ pero la mayoría de su obra permanece en España. Con este último hallazgo podemos añadir a su catálogo dos obras parisinas, las primeras localizadas en Francia.

Odile Delenda

Wildenstein Institute

\section{DE "PICTURA POESIS" A "EST ESUS": LAS VICISITUDES ICONOGRÁFICAS DE UN INÉDITO VALDÉS LEAL}

Hacia 1660 el pintor sevillano Juan de Valdés Leal da comienzo una importante serie iconográfica dedicada a la vida del fundador de la Compañía de Jesús, San Ignacio de Loyola ${ }^{1}$. Estos lienzos destinados a decorar los paños del patio de la Casa Profesa de los Jesuitas de Sevilla tenían una doble función didáctica y moralizante al igual que los abundantes conjuntos pictóricos encargados por las órdenes religiosas en la España del siglo XVII.

Además de esta serie biográfica de San Ignacio hay un segundo grupo de pinturas de contenido alegórico donde se desarrolla una compleja iconografía jesuítica de difícil lectura dirigida posiblemente a los miembros de la misma orden ${ }^{2}$. Como ha señalado Enrique Valdivieso $^{3}$ estas dos obras pertenecerían a un segundo contrato de 1676 cuando Valdés Leal llega a un acuerdo con los jesuitas para completar el conjunto iconográfico de la Casa Profesa de Se-

11 Palomino A., El Parnaso... op. cit., p. 478.

12 Ponz A., Viaje de España, t. V, [1776], ed. 1972, pp. 62-63 y 281, 285.

${ }^{13}$ Ceán Bermúdez J.A., Diccionario..., Madrid, 1800, ed. 1965, pp. 48-49.

\footnotetext{
' Para el estudio de la obra del pintor y la serie de cuadros para la Casa Profesa de los Jesuitas de Sevilla véase Enrique Valdivieso, Juan de Valdés Leal, Sevilla, 1998, pp. 106-117.

${ }^{2}$ Ibídem, p. 117

${ }^{3}$ Ibídem, p. 117
} 